\begin{tabular}{|c|c|}
\hline 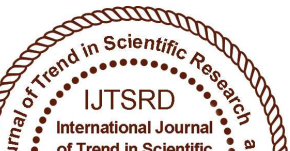 & $\begin{array}{l}\text { International Journal of Trend in Scientific } \\
\text { Research and Development (IJTSRD) }\end{array}$ \\
\hline 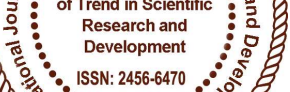 & International Open Access Journal \\
\hline 000 & ISSN No: 2456 - 6470 | www.ijtsrd.com | Volume - 2 | Issue - 3 \\
\hline
\end{tabular}

\title{
Waste Water Generating Electricity by Using Microcontroller
}

\author{
Prof. M. R. Dhavale, Prof. S. J. Kulkarni, Prof. S. N. Jadhav \\ Department of Electronics and Telecommunication P. Dr. V. V. Patil Institute of Technology and Engineering \\ (Polytechnic), Loni, Ahmednagar, Maharashtra, India
}

\begin{abstract}
Hydropower is one of the most promising available energy sources in the world. It accounts for almost 16 percent of global electricity consumption. It is clean and renewable energy source as compared to fossil fuel based generation which pollute environment. At the time of floods there will be a huge flow which will causes damage to the plant, inefficient power generation. So these are avoided by using automation. Before the existence of the automation, qualified personnel operated the equipment manually. This was called Manual System. By incorporating automation in hydro power plant, it reduces the manual labor as well as increases the efficiency of the operations performed like providing more flexibility of changing the mode of operation, for example, Power Control, Level Control. It enables to control the plant from a remote area.
\end{abstract}

This paper deals with the use of micro controller for control and automation of hydro power plant, its advantage and cost effectiveness. Here, we are using wired method to transmit measured generated power and water level in the water reservoir along with a controller for automation of opening and closing of shutter for emergency purpose.

Keywords: Voltage sensor, LDR, Microcontroller, LCD, Turbine

\section{INTRODUCTION:}

In this age increasing demand of energy has forced us to look at the other options different from conventional means of exploiting energy as conventional sources of energy are exhaustible. The beauty of these renewable energy systems is that they are non-exhaustible. Of all the non-conventional renewable energy sources, hydro represents the 'highest density' resource and stands in the first place in generation of electricity from such sources throughout the world.

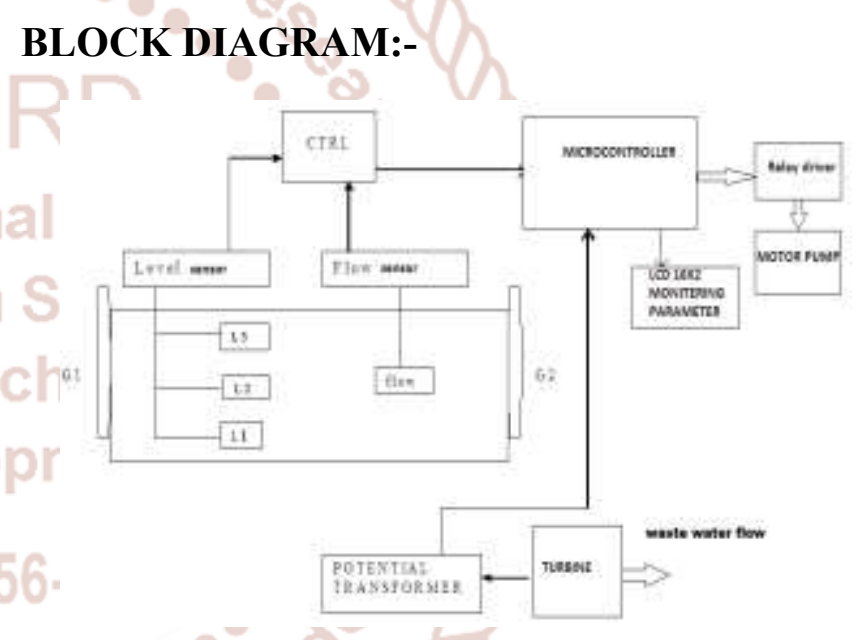

WORKING:-

In this project the water level sensor, Flow sensor is placed in the water. These are the float type sensor and one type transducer it generate voltage signals depends upon the water level then these signal is given to signal and conditioning unit. Signal conditioning circuit consists of op amp in which the incoming signal is amplified and conditional then output signal is given to ADC.

$\mathrm{ADC}$ is nothing but analog to digital converter. It is the 8 bit ADC. So it converts the incoming analog signal into digital signal then corresponding signals are fed to the micro controller. Here the microcontroller may be ATMEL/PIC/ $\$ 8082$ microcontroller. It will work according to our object already we have programmed. 
Dam open and close model is connected to motor along with mechanical arrangement then the motor is connected to relay. Relay driver circuit consists of transistors, which acts as switch on. So it can control the relays on / off times. Depends up on the Level, flow values motor is operated through the relay.

\section{CIRCUIT DIAGRAM:-}

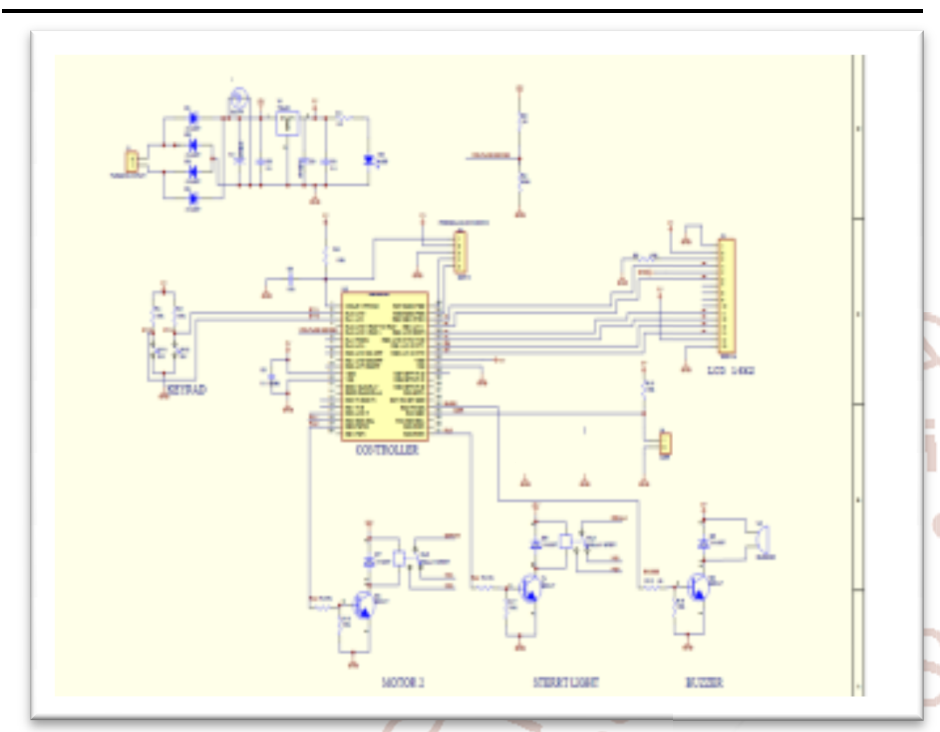

APPLICATIONS:-

* It is used in a wide range of industries.

* It is used in generation of electric power.

* It is used to control the floods in river.

* It is used to management of the waste water.

ADVANTAGES:-

* Water is cheapest and reliable source of generation of electric power.

* Reducing the man power.

* Save the more energy.

* No fuel transportation problem.

* Its maintenance cost is low.

DISADVANTAGES:-

* Requires flowing water

* Distrupts the ecosystem

* Reservoirs can fill with dirt and become useless

\section{FUTURE SCOPE:-}

* This project has a good future scope as it can be implemented on large scale for generation of electricity on small scale for domestic use or for industries on small scale.

* This can be implemented on small rivers and canals, which have some amount of water in it.

* This is an economical project as it just requires initial investment and has serving of many years.

* This would not solving electricity problems across India even in rural areas reduce consumption of non-renewable sources.

\section{RESULT:}

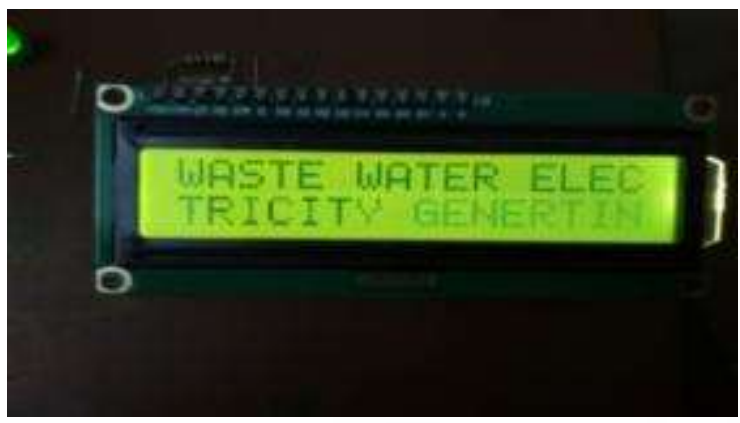

Fig 1. Waste Water Electricity generation

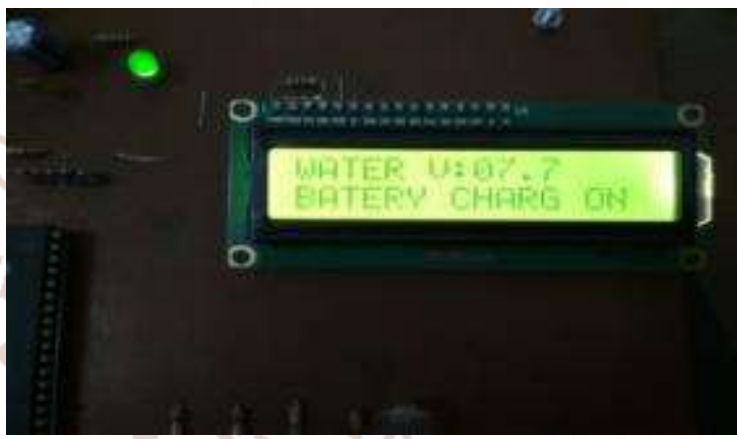

Fig 2. Battery charging on condition.

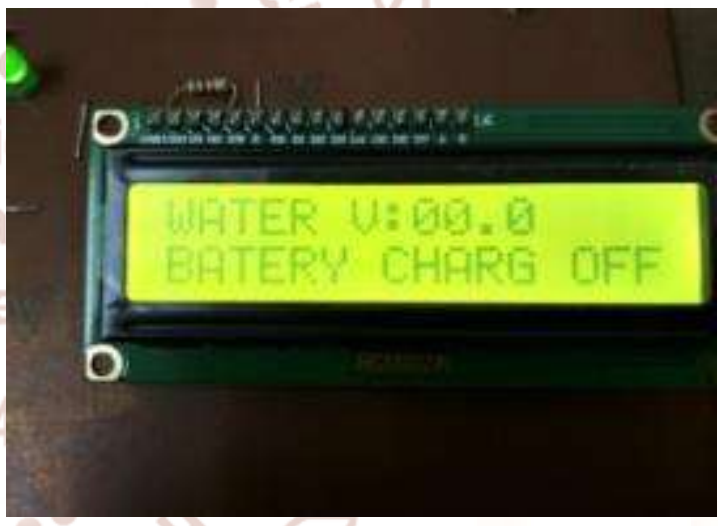

Fig 3. Battery charging off condition.

\section{CONCLUSION:-}

* Waste water electricity generation is a direct energy conversion system, which convert AC supply into DC supply energy.

* By this generation technique large power is generated without any pollution by waste water.

\section{REFERENCES:-}

1) Automation of Small Hydro Power station, Raju Gupta, S.N. Singh and S.K. Single.

2) http://www.iccee.co.in/papers/ICCCECS654.pdf

3) http://www.youtube.com/watch?v=sSAuD9IFB_8 